Moreira, Tiago de Almeida. Representações sobre a mulher no cinema brasileiro contemporáneo. GeoGraphos [En línea]. Alicante: Grupo Interdisciplinario de Estudios Críticos y de América Latina (GIECRYAL) de la Universidad de Alicante, 2 de agosto de 2015, vol. 6, $\mathrm{n}^{\mathrm{o}}$ 80, p. 180-201. [ISSN: 2173-1276] [DL: A 371-2013] [DOI: 1014198GEOGRA2015.6.80].

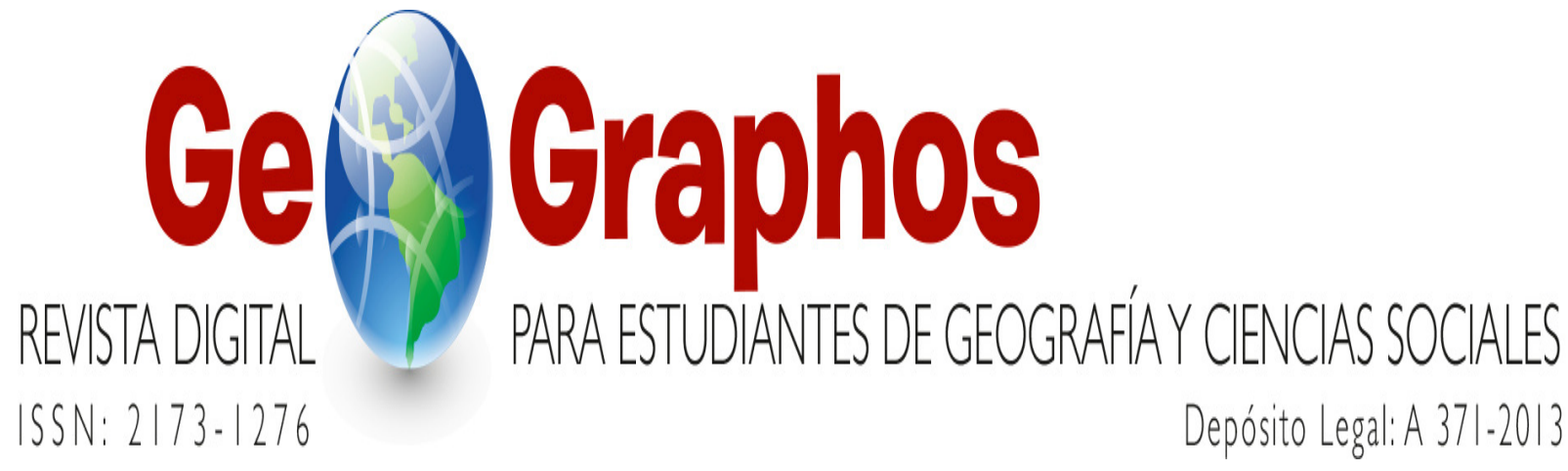

<http://web.ua.es/revista-geographos-giecryal>

Vol. 6. $\mathrm{N}^{\circ} 80$

Año 2015

\title{
REPRESENTAÇÕES SOBRE A MULHER NO CINEMA BRASILEIRO CONTEMPORÂNEO
}

\author{
Tiago de Almeida Moreira \\ Doutorado em Geografia \\ Laboratório de Geoiconografia e Multimídias. Departamento de Geografia. \\ Universidade de Brasília (Brasília, Brasil) \\ Correio eletrônico: tiagoalmeidamoreira@gmail.com
}

Recibido: 6 de marzo de 2015. Devuelto para revisión: 16 de abril de 2015.

Aceptado: 2 de agosto de 2015

\section{RESUMO}

$\mathrm{O}$ artigo apresenta e analisa um inventário com vinte e cinco filmes brasileiros contemporâneos que fazem representações sobre a mulher. As elaborações ficcionais sobre a mulher no cinema evidenciam que o seu papel na sociedade tem se modificado. Se em outros tempos do cinema brasileiro o feminino já foi tratado como o sexo frágil, associado à idéia de 
mulher objeto, submissa ao homem, nos filmes atuais a mulher tem assumido um papel de protagonista nas relações de gênero.

Palavras chave: Geografias de cinema, relações de gênero, representações sobre a mulher.

\title{
REPRESENTACIONES SOBRE LA MUJER EN EL CINE BRASILEÑO CONTEMPORÁNEO
}

\section{RESUMEN}

El artículo presenta e analiza un inventario con veinticinco películas brasileñas contemporáneos que hacen representaciones acerca de la mujer. Las elaboraciones ficcionales acerca de la mujer en lo cine comproban que su papel en la sociedad hai se alterado. Se en otros tiempos de lo cine brasileño lo feminino fue tratado como o sexo frágil, associado a la idea de mujer objeto, sumisa a lo hombre, en los películas corrientes la mujer tiene asumido un papel de protagonista em las relaciones de género.

Palabras clave: Geografías de cine, relaciones de género, representaciones sobre la mujer.

\section{REPRESENTATIONS ABOUT THE WOMAN ON THE BRAZILIAN CONTEMPORARY CINEMA}

\begin{abstract}
The paper presents and analyses an inventory with twenty five Brazilian contemporary movies which makes representations about the woman. The fictional elaboration about the woman on cinema shows that your paper on the society has being changed. If in another times of the Brazilian cinema the female was treated as the fragile sex, associated to the idea of object woman, submitted to the man, on the actual films the woman have assumed a paper of protagonist in the gender relationships.
\end{abstract}

Key Words: Geographies of Cinema, Gender Relationships, Representations about the Woman.

\section{INTRODUÇÃO}

As relações de gênero influenciam no papel da mulher e do homem na sociedade, sobretudo em países com uma arraigada cultura machista como o Brasil. As representações fílmicas sobre a mulher no cinema podem servir tanto para influenciar na mudança de paradigmas nas relações de gênero, como também para reforçar certos estereótipos sexistas sobre a mulher. Se em outros tempos a mulher brasileira era representada no cinema associada à ideia de sexo frágil, objeto sexual, submissa ao homem, nos filmes contemporâneos esta imagem tem sido 
modificada. O artigo propõe um olhar geográfico acerca de representações sobre a mulher no cinema brasileiro contemporâneo.

A “análise de discurso", proposta por Foucault (1996), é a referência teórico-metodológica utilizada neste estudo, e visa identificar e escrutinar discursos subjacentes a um discurso original, gerando um comentário que irá compor um novo discurso. A técnica de pesquisa empregada foi a de análise de conteúdo, discutida por Marconi e Lakatos (2006), sendo, neste caso, os filmes citados tomados como objetos de estudo. As análises buscarão a responder a três questões norteadoras: 1. De quais formas a mulher tem sido representada no cinema brasileiro contemporâneo? 2. As representações fílmicas contemporâneas sobre a mulher rompem com paradigmas sexistas a respeito dela ou reforçam velhos estereótipos? 3. O que se pode concluir, de maneira geral, acerca das análises de representações fílmicas sobre a mulher a partir dos vinte e cinco filmes apontados neste artigo?

O artigo está subdividido em três outras seção além da introdução. O tópico seguinte faz uma revisão de trabalhos que analisam representações sobre a mulher no cinema, o penúltimo tópico apresenta e analisa o inventário fílmico que trata de representações sobre a mulher, já o último capítulo trás as considerações finais, seguidas das referências e da filmografia utilizada.

\section{ANÁLISES DE REPRESENTAÇÕES SOBRE A MULHER NO CINEMA}

As imagens da mulher no cinema brasileiro de 1896 a 1928 a representavam exercendo um papel à margem das decisões, figurando como vítima ou paciente da ação. Em alguns filmes, nos quais era a personagem central da história, era invariavelmente conduzida por um par romântico (Furtado, 2006). Esta imagem esteve presente não apenas neste período, de virada do Século XIX para o XX, mas ao longo deste último século, até a década de 1970. Sobretudo nos filmes da antiga produtora Vera Cruz, e nas Pornochanchadas, a mulher era representada como sendo o sexo frágil, o objeto sexual a ser desejado e subjugado pelo homem.

O star system norte americano, ou seja, o tratamento midiático dado aos astros e estrelas de Hollywood durante a primeira metade do século passado, ajudou a difundir uma imagem da mulher como cativa e aprisionada a um conceito de mulher ideal. Esta visão foi amplamente explorada pelo mercado de consumo da época, e teve suas influências no papel da mulher na sociedade, sobretudo no ocidente (Gubernikoff, 2009). Esta imagem propalada pelo star 
system americano influenciou sobremaneira a fase inicial do cinema brasileiro, do início do século passado até a década de 1950.

A televisão e o cinema têm contribuído muito para a construção do imaginário social a respeito de sexo e gênero, e, sobretudo, à imagem da mulher e do seu papel na sociedade. A mídia, à medida que representa gêneros, institui valores, propões estilos de vida, informa sobre as coisas com que se deve sonhar e desejar. Ao representar o gênero feminino de uma forma estereotipada, o cinema e a televisão mostram-se tecnologias instituidoras de um binarismo masculino $\mathrm{x}$ feminino, de uma naturalização da submissão feminina, e, em muitos casos, de um sexismo exacerbado (Machado, 2006).

A imagem da mulher brasileira no cinema passa a se modificar ao longo do período da ditadura militar no Brasil, de 1964 a 1985, quando cineastas mulheres passam a realizar filmes e a representar a si mesmas diante das intensas mudanças culturais e comportamentais deste período (Silva, 2012). Este processo de apoderamento das mulheres na produção de filmes, e da representação de si mesmas, esteve presente não apenas no Brasil, mas também na Venezuela (Olivares, 2010), na Colômbia (Quintero, 2010), e em outros países da América Latina. Esta região passava por períodos de autoritarismo militar e, ao mesmo tempo, o mundo passava por grandes mudanças de paradigmas no que tange às relações de gênero, e, o cinema necessitava acompanhar as mudanças sobre o papel da mulher na sociedade, e ninguém melhor do que cineastas mulheres para representar esse processo.

Os anos de 1980 foram de ostracismo produtivo no cinema brasileiro, por conta da inflação descontrolada, que onerava em muito os custos de produção, e também por conta da extinção da Embrafilmes, antiga empresa estatal que fomentava a produção de filmes. A partir da segunda metade dos anos 1990 inicia-se o período chamado de Retomada do Cinema Nacional, e desde o início deste século XXI a produção nacional ganhou novo fôlego e se consolidou, como uma indústria diversa, estruturada e efervescente em sua produção e veiculação.

O contexto atual do cinema brasileiro passa a tratar as representações sobre a mulher de maneira menos estereotipada, tratando temas como a maternidade de maneira menos simplificadora que boa parte dos filmes do século passado (Azevedo, 2011). A crítica ao estupro enquanto norma de gênero tem sido abordada em diversos filmes contemporâneos (Luna, 2006). O papel da mulher negra no cinema nacional tem ganhado novas abordagens, menos associadas ao estereótipo da mulata brasileira vista como objeto sexual, abrindo 
perspectivas para o seu protagonismo na sociedade atual (Lahni, 2007). Estes e tantos outros temas a respeito da mulher têm sido trazidos à baila pelo cinema, e este artigo pretende contribuir com esta questão, a partir das análises a serem apresentadas no tópico a seguir.

\section{A MULHER NO CINEMA BRASILEIRO CONTEMPORÂNEO}

Os vinte e cinco filmes a serem arrolados a seguir serão apresentados em blocos temáticos, cada um destes tratando de algum assunto específico, podendo conter apenas um filme ou vários, a depender da semelhança entre as temáticas gerais de cada filme.

\section{A persistente imagem da mulher enquanto objeto de desejo sexual}

A despeito de todas as mudanças culturais e comportamentais dos últimos trinta anos, alguns filmes brasileiros ainda trazem a representação fetichista e sexista da mulher enquanto objeto sexual, associada à ideia da mulher enquanto posse do homem. Dois filmes em particular trazem esta abordagem: Crime delicado, de Beto Brant - 2006, e A mulher invisível, de Cláudio Torres - 2009.

No primeiro filme, Inês é uma bela mulher que teve uma das pernas amputadas, ver Figura 1, e que é a única modelo viva para o pintor José Torres Campana. Inês conhece e se envolve com Antônio, que a despeito de sua condição amputada, enxerga nela a sua companheira ideal. Ela se vê dividida entre estes dois homens, um que a deseja por motivos estéticos, por ser sua musa inspiradora, e outro que está apaixonado por ela. Os dois homens passam a disputar uma pretensa posse e exclusividade sobre Inês, e a sua vontade pessoas fica em segundo plano nesta disputa.

Já no filme A mulher invisível, Pedro é um jovem romântico e apaixonado por sua namorada de anos, e entra em depressão quando ela termina o relacionamento anunciado que está envolvida com outro homem há algum tempo. Em seu estado depressivo, Pedro acaba criando uma mulher imaginária, Amanda, ver Figura 2, que é linda, prendada e totalmente submissa a Pedro, é praticamente uma escrava sexual. Um amigo, percebendo o estado de desequilíbrio do protagonista, tenta mostrá-lo que esta mulher idealizada e quase que perfeita só existe na cabeça dele. 
Figura 1. A mulher como objeto de desejo Figura 2. A idealização sexista da mulher
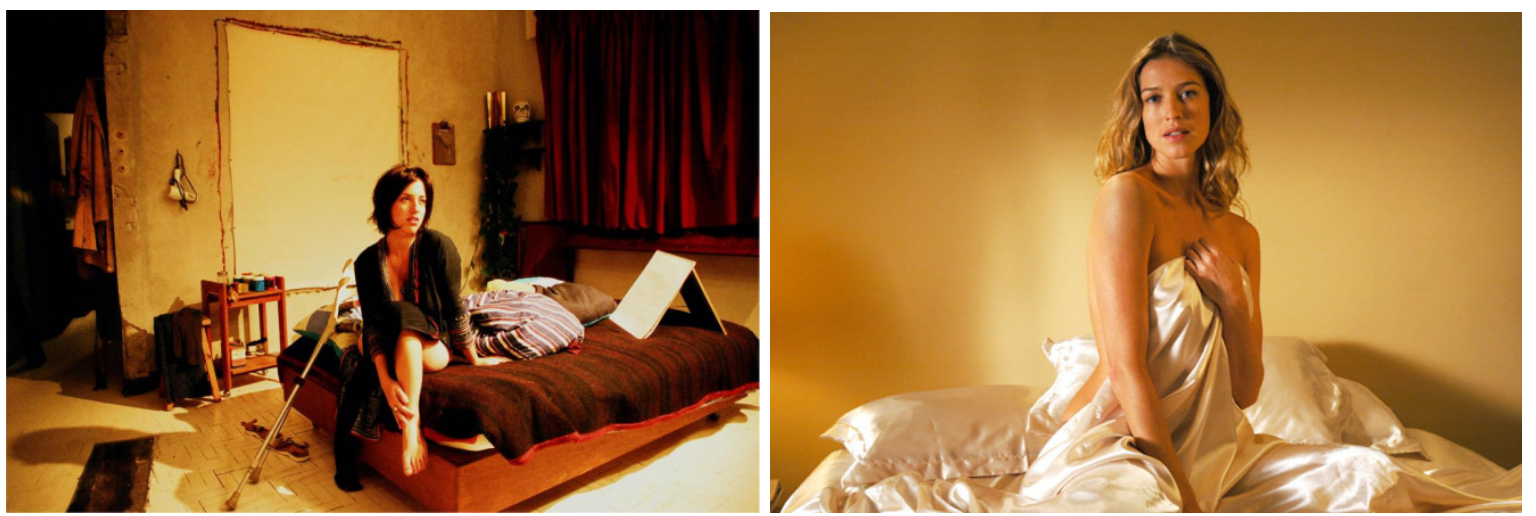

Fonte: Site www.adorocinema.com.br (para as duas imagens).

Os dois filmes citados acima tratam da visão da mulher enquanto objeto de desejo, porém, de maneiras completamente diferentes. Enquanto no filme Crime delicado é abordada uma crítica ao estereótipo sexista em relação à mulher, a partir do questionamento do sentimento de posse que dois homens têm pela protagonista, em A mulher invisível o estereótipo da mulher objeto é tratado de maneira simplista, e, em muitos momentos, é até exaltado, como uma qualidade a ser incorporada pelas mulheres.

Na sociedade brasileira atual há um paradoxo a respeito desta questão: ao mesmo tempo que muitas mulheres não admitem ser tratadas como objetos de desejo, e lutam por mudar esta imagem, outras, sobretudo aquelas que orbitam o universo das celebridades e subcelebridades midiáticas, adotam explicitamente esta auto imagem e conquistam fama relativa única e exclusivamente pela exibição exagerada de seus corpos.

\section{A exploração sexual feminina}

A prostituição feminina e a exploração sexual da mulher é um tema complexo e polêmico, sobretudo no Brasil, um país que no contexto internacional carrega a imagem de ser conivente com a questão do turismo sexual em muitas capitais brasileiras. Três filmes tratam da exploração sexual feminina: Anjos do sol, de Rudi Lageman - 2006, Sonhos roubados, de Sandra Werneck - 2010, e Bruna Surfistinha, de Marcus Baldini - 2011.

O primeiro dos filmes citados trata de adolescentes nordestinas que, assim como a personagem Maria, ver Figura 3, são vendidas por seus pais e ou tutores para serem 
exploradas sexualmente em garimpos clandestinos na região amazônica. O segundo filme mostra o cotidiano de jovens moradoras de favelas cariocas que, assim como Jéssica, ver Figura 4, são impelidas à prostituição, para ajudar as despesas de casa, criar seus filhos gerados em gravidez na adolescência, além de pagar seus consumos pessoais. Já o filme Bruna Surfistinha, baseado em fatos reais, conta a história de uma adolescente criada por uma família adotiva, na qual ela não se sente totalmente acolhida, que resolve sair de casa e entrar para o universo da prostituição de alto luxo na cidade de São Paulo, ver Figura 5.

Figuras 3, 4 e 5. Maria, Jéssica e Bruna - diferentes faces da exploração sexual feminina

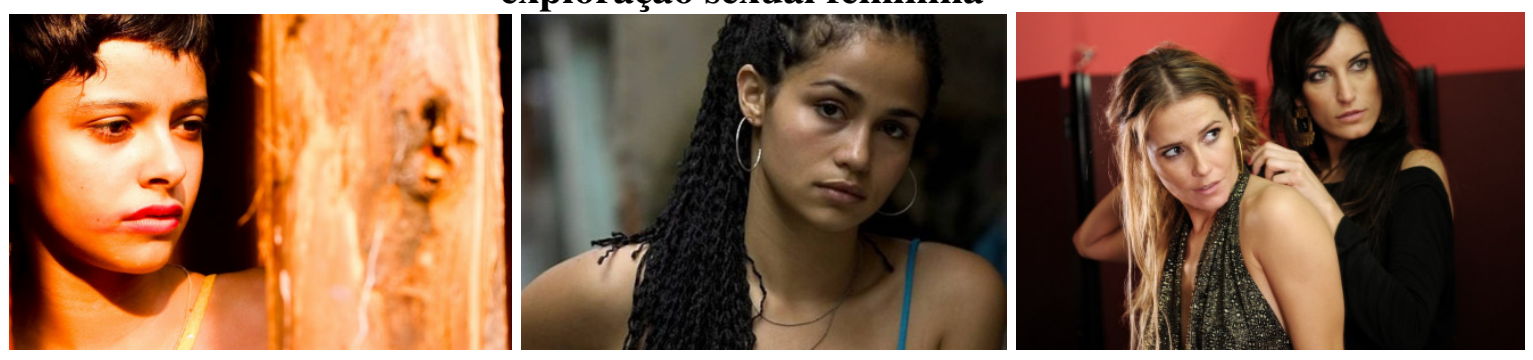

Fonte: Site www.adorocinema.com.br (para as três imagens).

Os três filmes citados abordam de forma crítica e sensível os fatores que influenciam na prostituição feminina, seja a prostituição forçada de menores de idade, retratada em Anjos do sol, seja a prostituição por necessidades financeiras, abordada em Sonhos roubados, ou seja a prostituição como opção de vida, como é mostrada na cinebiografia Bruna surfistinha.

\section{A mulher e a questão do crime}

O envolvimento da mulher com o crime é o tema de dois filmes: Jogo de xadrez, de Luis Antonio Pereira - 2014, e Nina, de Heitor Dhalia - 2004. O primeiro filme mostra o cotidiano de um presídio feminino, no qual a estelionatária Mina, ver Figura 6, luta para sobreviver a toda a violência da carceragem, e reduzir a sua pena, através da denúncia do envolvimento de um senador na fraude cometida por ela.

Já o filme Nina, livremente inspirado no livro Crime e Castigo, de Fiodór Dostoiévski, conta a história da jovem protagonista, que aluga um quarto de moradia na cada da autoritária Dona Eulália. A falta de perspectivas de trabalho para a protagonista, aliado à tensão constante e aos 
conflitos recorrentes entre as duas, faz com que Nina passe a ter pensamentos paranóicos, ver Figura 7, o que a leva a cometer um homicídio contra Dona Eulália.

Figura 6. A mulher presidiária

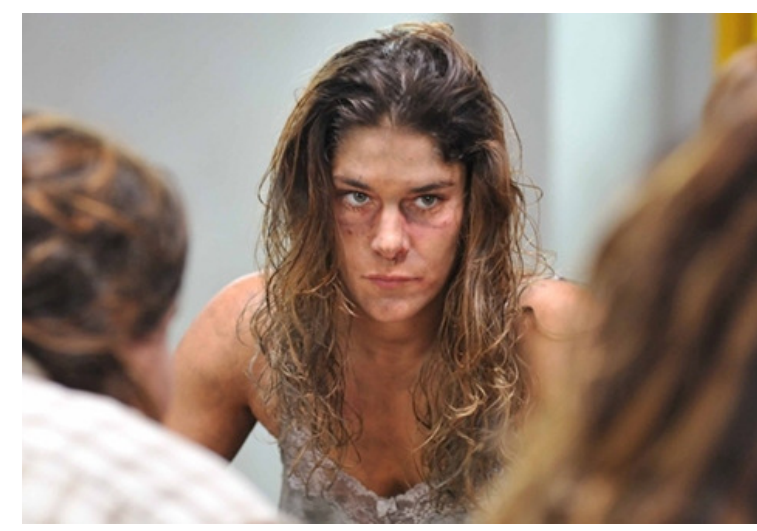

Figura 7. O impulso criminoso

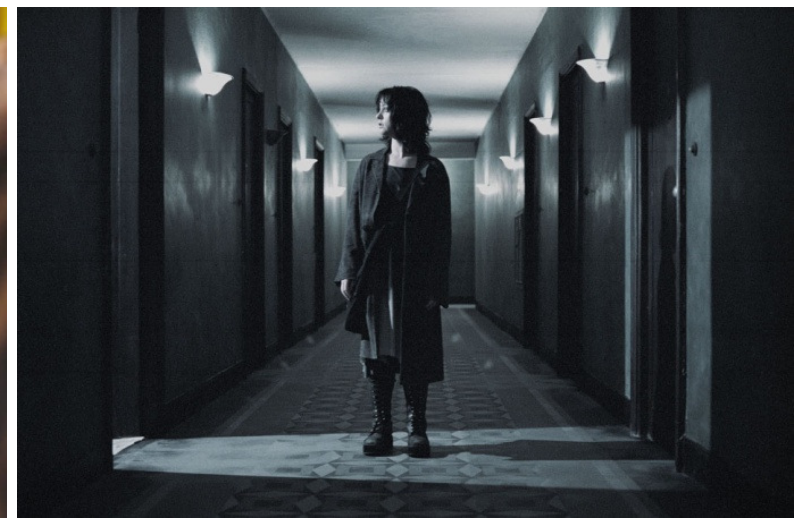

Fonte: Site www.adorocinema.com.br (para as duas imagens).

O número de homens envolvidos com a criminalidade é bem maior do que o número de mulheres, como é amplamente divulgado pela mídia, e como ocorre não apenas no Brasil, mas em maior parte dos países. Porém há, nos dias atuais, um número expressivo de mulheres que acabam se envolvendo em alguma atividade criminosa, e este é um tema relativamente ainda pouco explorado no cinema brasileiro contemporâneo.

\section{A mulher negra da periferia}

Os anseios e dilemas da jovem mulher negra moradora de uma periferia paulista é o tema do filme Antônia, de Tata Amaral - 2006. Quatro amigas, Barbarah, Lena, Preta e Mayah, ver Figura 8, são amigas de infância que moram na Vila Brasilândia, periferia de São Paulo, e sonham em viver de música. Quando são descobertas e passam a ser produzidas pelo empresário Diamante, vêem o sonho de se tornar artistas começar a se concretizar, à medida que passam a fazer shows e a gravar o primeiro disco. Porém, para que isto aconteça de fato, terão que lutar contra o cotidiano de violência das periferias, o machismo de namorados e parentes, e a pobreza em que vivem, que também afeta o grupo. 
Há uma infinidade de filmes contemporâneos que retratam o cotidiano das periferias, sobretudo das periferias cariocas, e na maioria desses filmes é dado pouco papel de destaque às mulheres, quase sempre os homens são os representados como os protagonistas da periferia. Este filme subverte essa tendência, retratando jovens mulheres negras como atuantes em sua comunidade, e agentes de seus próprios projetos de vida.

\section{Figura 8. As mulheres negras da periferia e seus sonhos}

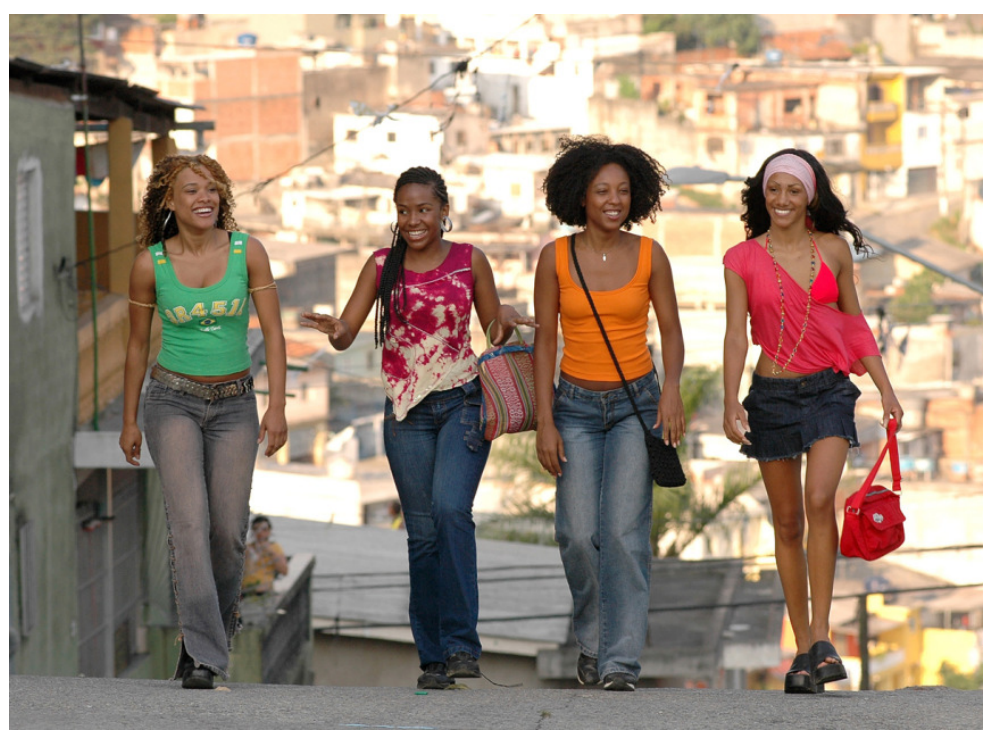

Fonte: Site www.adorocinema.com.br

\section{A homoafetividade feminina}

A questão da homoafetividade feminina é representada em três filmes: Como esquecer, de Malu de Martino - 2010, Elvis \& Madona, de Marcelo Laffitte - 2011, e Paraísos artificiais, de Marcos Prado - 2012. No primeiro filme, Júlia, ver Figura 9, é uma professora de literatura, que foi abandonada por sua companheira de mais de dez anos de relacionamento, e acabou entrando em depressão, e, com a ajuda do amigo Hugo, tenta retomar o ânimo em sua vida.

No segundo filme, Elvis, ver Figura 10, é uma jovem fotógrafa, lésbica, que acaba se envolvendo e engravidando do cabeleireiro e travesti Madona. Juntos, eles terão que lutar contra o preconceito da família e da sociedade, para poderem viver o seu relacionamento plenamente, além de reavaliar radicalmente as suas concepções sobre identidade de gênero e orientação sexual. 
Em Paraísos artificiais, Érika é uma jovem DJ, bissexual, que tem um relacionamento descompromissado com sua amiga Lara, ver Figura 11, amiga esta que acaba morrendo de overdose em uma festa de música eletrônica, logo depois de as duas terem feito um ménage a trois com um jovem que conheceram ao acaso. Este evento levou à morte de Lara, mas também à gravidez de Érika, e mudou completamente sua forma de se relacionar afetivamente.

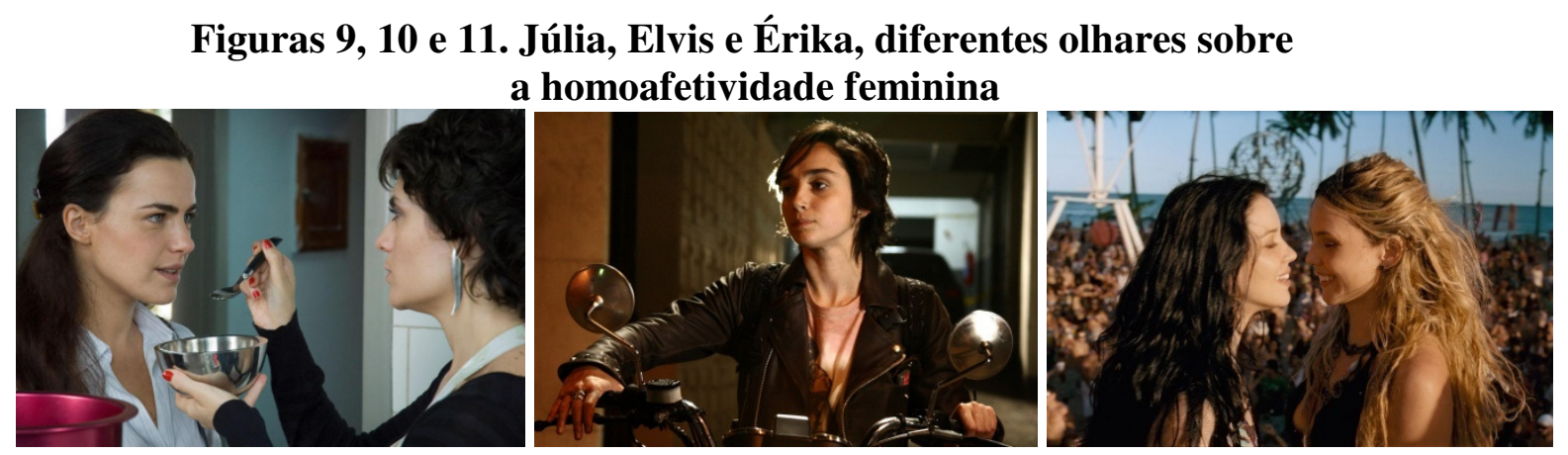

Fonte: Site www.adorocinema.com.br (para as três imagens).

A homoafetividade feminina é um tema delicado e ainda pouco explorado no cinema brasileiro contemporâneo, e os três filmes citados abordaram esta questão a partir de vieses diferentes, que se complementam para um entendimento mais abrangente da questão: em Como esquecer o foco está na dificuldade de uma mulher lésbica achar o seu lugar no mundo, a partir do término de um relacionamento de muitos anos; em Elvis \& Madona o foco está na quebra da dicotomia homem x mulher, na relativização a respeito das identidades de gênero masculino e feminino; já em Paraísos artificiais o foco está no impasse que a protagonista bissexual vive em relação às suas escolhas amorosas, entre a maternidade e a necessidade de liberdade.

\section{A mulher e o romantismo no mundo contemporâneo}

Representações do romantismo feminino contemporâneo, através de jovens mulheres operárias, moradoras de periferias de São Paulo, foi o tema explorado pelo cineasta Carlos Reichenbach em dois de seus filmes: Falsa loura, de 2008, e Garotas do ABC, de 2004. No primeiro filme, Silmara, ver Figura 12, cuida do pai idoso, que teve o corpo deformado por 
conta de um incêndio, trabalha muito para sustentar a família, e tem o sonho romântico de conhecer pessoalmente o seu ídolo, um galã das telenovelas.

Já no filme Garotas do $A B C$, Aurélia e suas amigas, ver Figura 13, são operárias de uma indústria têxtil na região do $\mathrm{ABC}$ paulista, e todas elas, além da luta diária pela sobrevivência, são movidas, sobretudo, pelo romantismo. A protagonista Aurélia, uma jovem negra, namora com Fábio, que, com o desconhecimento dela, participa de um grupo neonazista que persegue negros e nordestinos da região. O romantismo é o fio condutor nas histórias de cada uma dessas garotas de periferia.

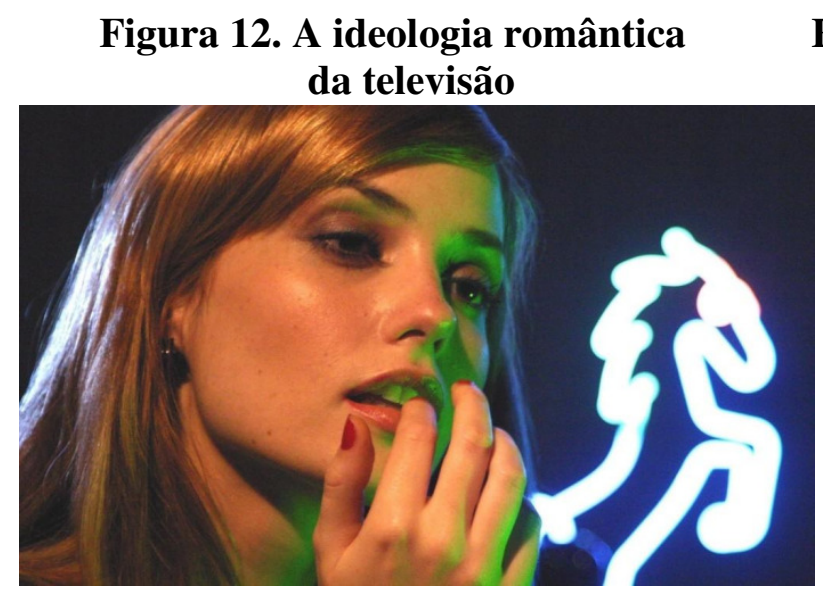

Figura 13. Romantismo e questões étnicas

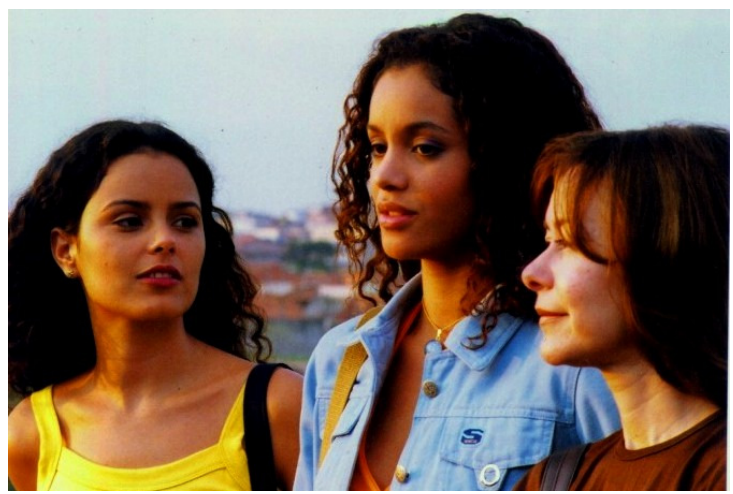

Fonte: Site www.adorocinema.com.br (para as duas imagens).

O cineasta mostra que, apesar de o romantismo estar, aparentemente, fora de moda em tempos atuais, para muitas jovens de periferia, que não têm as mesmas condições de ingressar em uma formação acadêmica, e de desenvolver uma carreira profissional, como as garotas de classe média, o sonho romântico de encontrar um parceiro ideal é um dos poucos sonhos que elas podem alimentar. A abordagem dos dois filmes é, em certo ponto, melodramática em excesso, apelando para recursos narrativos amplamente utilizados nas telenovelas brasileiras, tratando de maneira superficial os dilemas e conflitos das personagens.

A perspectiva do romantismo contemporâneo sob a ótica de duas jovens mulheres de classemédia foi retratado em dois filmes: Entre lençóis, de Gustavo Nieto Roa - 2008, e Confia em mim, de Michel Tikhomiroff - 2014. No primeiro filme, Paula é uma jovem de classe-média que está noiva, prestes a se casar vai fazer a sua despedida de solteira com as amigas em uma 
boate, onde, no final da noite, acaba conhecendo Roberto, que está em crise no casamento, e, com ele, vai passar uma tórrida noite de amor em um motel, ver Figura 14, e discutir sobre suas vidas e suas escolhas pessoais.

No segundo filme, Mari é uma promissora chefe de cozinha, que conhece e rapidamente se apaixona pelo carismático Caio, que a propõe uma sociedade para montar o seu tão sonhado restaurante. Mari acaba sendo vítima de um golpe armado por Caio, o qual foge com todas as suas economias e, a partir disto, desiludida amorosamente, e ludibriada financeiramente, ela vai buscar os meios que pode para reaver seu dinheiro e garantir que a justiça seja feita. Mari, que esteve um tempo fechada a relacionamentos amorosos, depois desta grande desilusão, se fecha mais uma vez para a possibilidade de se envolver com alguém.

Figura 14. Romantismo versus casamento

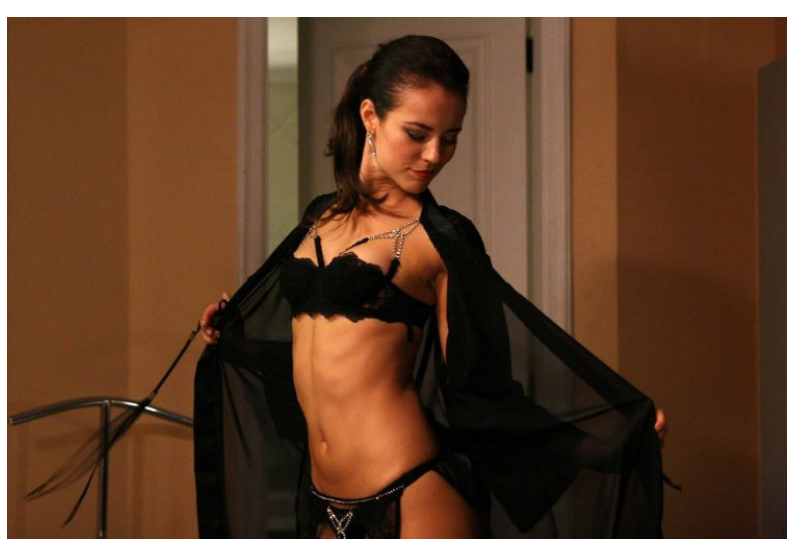

Figura 15. A desilusão romântica

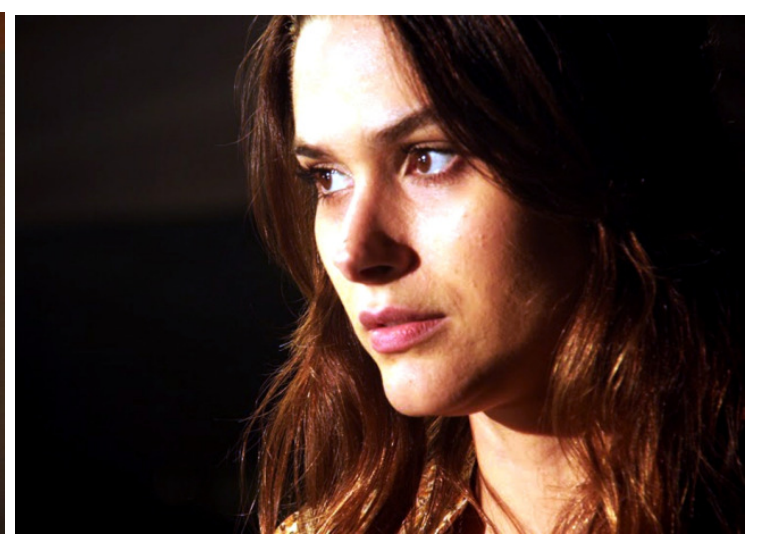

Fonte: Site www.adorocinema.com.br (para as duas imagens).

Os dois filmes trazem uma visão relativamente desencantada em relação ao romantismo na sociedade contemporânea. Em Entre lençóis, Paula vai se casar com um noivo ao qual ela não tem certeza se ama de verdade, e Roberto está em crise no casamento porque a convivência do matrimônio minou o amor que havia entre ele e a esposa, a mensagem geral que fica é a de que casamento e amor não são compatíveis em tempos atuais.

Já em Confia em mim, Mari, que vinha há algum tempo desiludida com relacionamentos amorosos, quando finalmente resolve se permitir a viver um se vê ludibriada por um golpista, e a mensagem real que fica é a de que o romantismo e o amor não compensam. Estas duas visões apresentadas fazem parte de uma perspectiva particular do diretor Carlos Reichenbach, 
e apontam que, de fato, boa parte das mulheres, atualmente, está bastante reticente em relação ao amor e ao romantismo.

\section{A mulher jovem e suas questões existenciais}

As questões existenciais da jovem mulher brasileira são abordadas em dois filmes: 3 Efes, de Carlos Gerbase - 2007, e Proibido proibir, de Jorge Duran - 2007. No primeiro filme, Sissi é uma jovem universitária, ver Figura 16, sustenta sozinha a casa na qual mora junto com o pai viúvo e depressivo e o irmão mais novo. Ela enfrenta os dilemas inerentes à fase de idade que vive, e às dificuldades de sobrevivência: priorizar o trabalho ou os estudos, priorizar a família ou a si mesma, manter um relacionamento desgastado ou abrir mão dele e seguir sua vida.

O filme Proibido proibir retrata a história de Letícia, ver Figura 17, uma jovem estudante universitária que namora com Leon, mas, acaba se apaixonando por Paulo, que divide casa com Leon. Este último dedica uma paixão verdadeira por Letícia, mas ela, sente-se intelectualmente atraída pelo culto e carismático Paulo. Alguns temas são levantados em meio a este triângulo amoroso: fidelidade nos relacionamentos, escolhas pessoais $\mathrm{x}$ escolhas profissionais, desencanto com seus cursos acadêmicos e sua real função social, dentre outros.

Figura 16. As escolhas de uma jovem

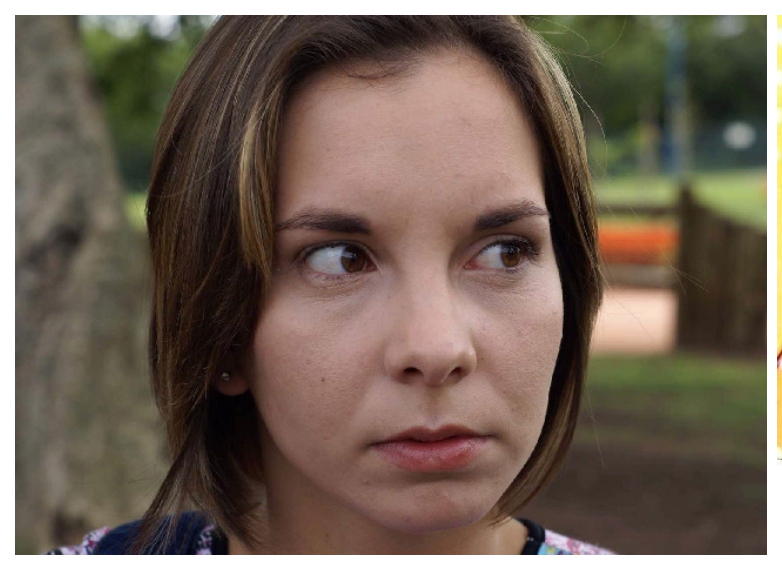

Figura 17. As incertezas da juventude

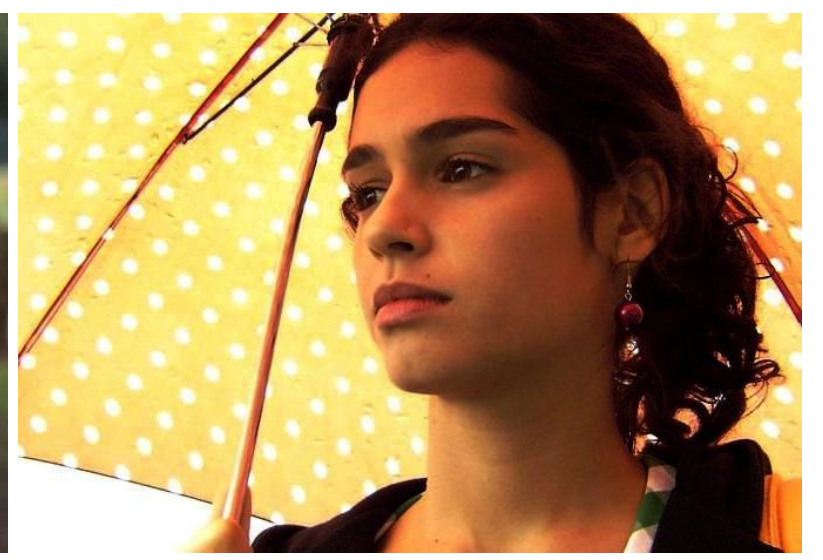

Fonte: Site www.adorocinema.com.br (para as duas imagens).

A busca da liberdade sexual e da realização pessoal no contexto machista do Nordeste brasileiro foram retratados em dois filmes: $O$ céu de Suely, de Karim Aïnouz - 2006, e Era 
uma vez eu Verônica, de Marcelo Gomes - 2012. O primeiro filme conta a história de Hermila, uma jovem de vinte e um anos de idade que, grávida, tenta a vida em São Paulo. Não consegue arrumar emprego e, ao se ver abandonada pelo seu companheiro, é obrigada a voltar para sua terra natal, no interior do Ceará, com o filho pequeno, ver Figura 18. Desiludida com o abandono por parte do namorado, e frustrada por ter que voltar para casa, Hermila resolve rifar o próprio corpo, ou melhor, uma noite de amor com o ganhador da rifa, a fim de juntar dinheiro para ir embora para o Rio Grande do Sul. Os sonhos de Hermila não são ganhar dinheiro e ter uma boa família, mas sim, ser feliz e viver um grande amor.

No filme Era uma vez eu Verônica, a protagonista vive uma fase de transição, ela mora com o pai idoso e adoentado, e acabou de se formar em Medicina. Sem tempo para a agitada vida que tinha quando era estudante, ela agora se dedica ao início da vida profissional em um ambulatório de hospital público. As condições são precárias e o cotidiano muito cansativo, e com a morte do pai, ela se vê sem referenciais no mundo, e passa a relatar em um diário seus maiores dilemas, sobretudo o impasse entre firmar um compromisso sério com seu namorado ou se permitir a viver outros relacionamentos sem maior envolvimento afetivo.

Figura 18. A busca feminina do amor

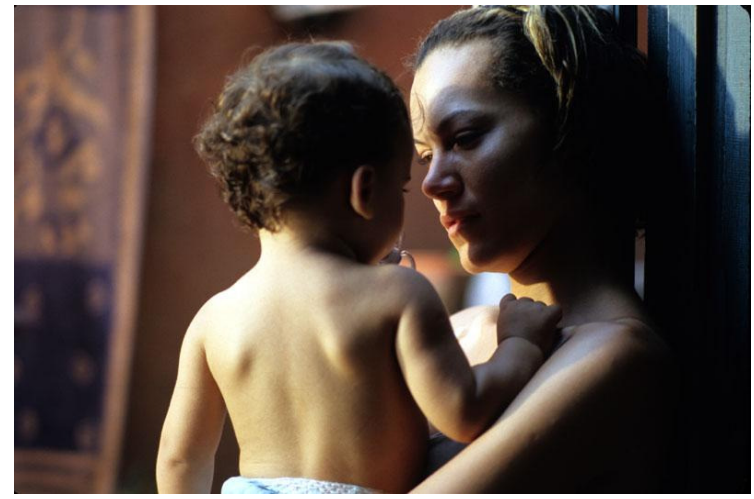

Figura 19. $O$ desejo de liberdade sexual

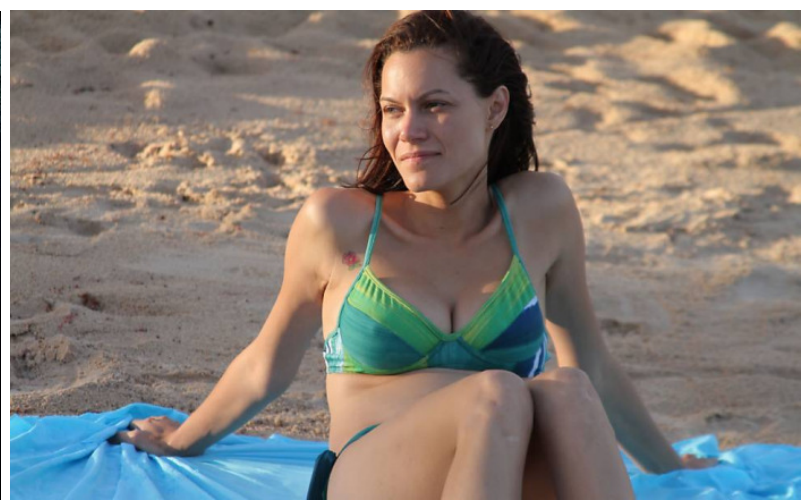

Fonte: Site www.adorocinema.com.br (para as duas imagens).

Os dois diretores dos filmes citados acima, ambos pernambucanos, têm, em seus filmes, tratado recorrentemente sobre o papel e os direitos da mulher na machista cultura nordestina. Ambos têm evidenciado que, a despeito de todas as mudanças culturais e comportamentais que têm havido no Brasil e no mundo, neste início de século XXI, no Nordeste a coerção social e moral em relação à mulher ainda se faz presente nos dias de hoje. 


\section{A mulher e a crise matrimonial}

A crise matrimonial entre mulheres de classe-média, bem sucedidas profissionalmente, mas com suas relações familiares em crise, é o tema de três filmes: Divã, de José Alvarenga Júnior - 2009, De pernas pro ar, de Roberto Santucci - 2011, e Onde está a felicidade?, de Carlos Alberto Riccelli - 2011.

No primeiro filme, Mercedes é uma mulher que tem uma vida aparentemente perfeita, ela é bonita, realizada profissionalmente, bem casada e mãe de dois filhos adolescentes. Diante disto tudo ela começa a se indagar se sua vida é realmente tão perfeita quanto aparenta, e para por à prova este questionamento ela resolve fazer terapia, e começa a perceber que sua vida é, de fato, cheia de problemas, problemas que ela insistia em não encarar, para que tudo continuasse parecendo perfeito, até que uma crise transformadora se instaura em sua vida.

O filme De pernas pro ar mostra a vida de Alice, uma mulher moderna e atribulada que, a princípio, só pensa em trabalho, dando pouca atenção a sua vida social e a sua família. Depois de ser demitida e abandonada pelo marido, ela muda radicalmente quando conhece sua vizinha Marcela, e junto com ela entra para o ramo de sex shops. O novo ramo de trabalho fará com que Alice aprenda a dar mais valor ao sexo e às pessoas, e inclusive a enxergar seu marido com outros olhos.

Já no filme Onde está a felicidade?, Teodora descobre que seu marido está mantendo uma relação virtual com outra mulher, e entra em crise, o que resulta na perda de seu trabalho como apresentadora de um programa culinário. Desiludida, ela resolve cair na estrada, e parte para uma viagem de autoconhecimento, percorrendo o Caminho de Santiago de Compostela. Esta jornada irá fazê-la rever totalmente os rumos e as prioridades em sua vida, a rever inclusive sua própria auto imagem, seus sonhos e desejos, alguns desses que foram sendo deixados de lado em função de uma carreira profissional.

Pode-se dizer que, grosso modo, os três filmes são variações sobre os mesmos temas: conflito de prioridades entre vida profissional e vida familiar, desgaste afetivo e sexual no casamento, busca de auto conhecimento diante da entrada na fase de menopausa, busca de auto estima. 
Figuras 20, 21 e 22. Mercedes, Alice e Teodora, a crise matrimonial na classe-média
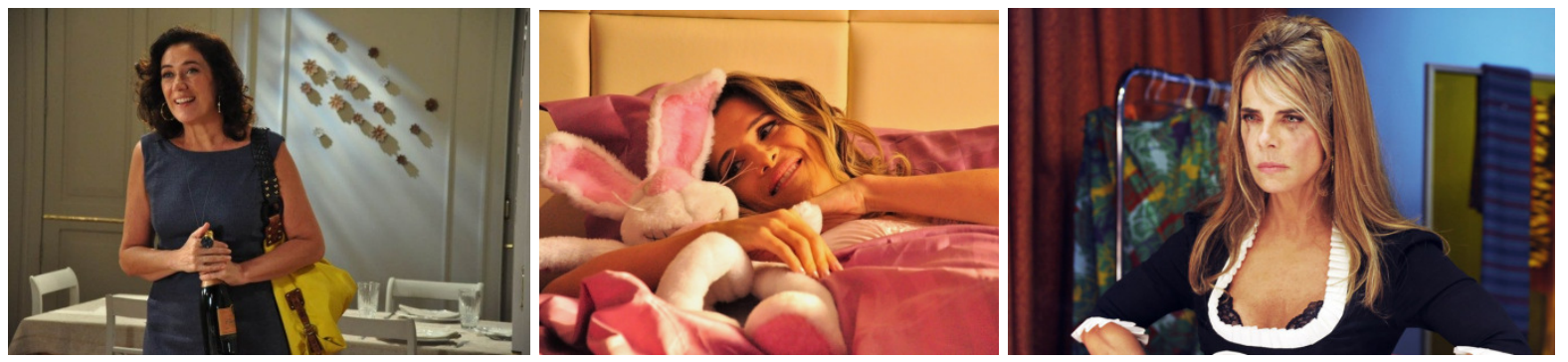

Fonte: Site www.adorocinema.com.br (para as três imagens).

A crise matrimonial em função do adultério feminino é o tema do filme Eu receberia as piores notícias dos seus lindos lábios, de Beto Brant e Renato Ciasca - 2011. Letícia, ver Figura 23, é uma ex-prostituta que foi tirada das ruas pelo benevolente pastor Ernani, o qual acha ser possível consertar as contradições humanas através da fé. Ao se casar com ele, Letícia encontra, na vida matrimonial, tudo aquilo que ela sempre procurou e nunca teve: carinho, amor e proteção. Porém, sua satisfação sexual é deixada em segundo plano nesta relação, e ela acaba tendo um caso com o sedutor Cauby, um fotógrafo que está fazendo uma reportagem sobre a Amazônia, no interior do Pará, onde Letícia vive.

Figura 23. A mulher adúltera e sua imagem na sociedade

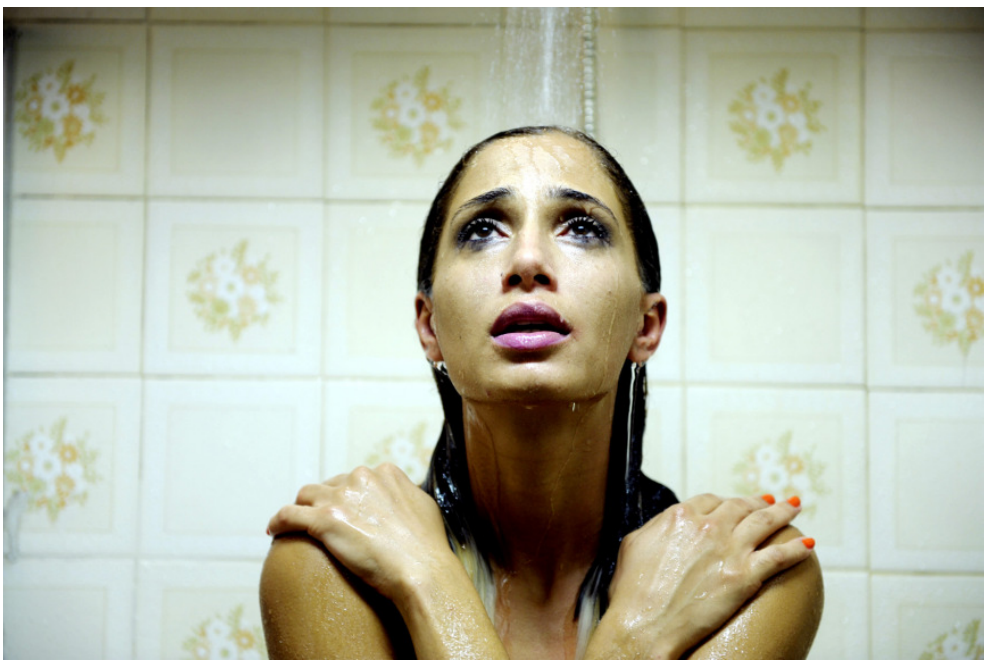

Fonte: Site www.adorocinema.com.br. 
O filme mostra que certas escolhas na vida são irreversíveis, e que toda escolha implica em uma renúncia: ao escolher abandonar a prostituição ela trocou a insegurança e a violência das ruas pela estabilidade de um casamento tradicional, mas teve, com isto, que abrir mão da sua satisfação sexual, em vista da falta de desejo do marido em relação a ela; ao escolher se permitir a viver um caso com Cauby, ela soube que teria que arcar com as consequências violentas que esta traição poderia acarretar. Um dos pontos fundamentais do filme é a questão do julgamento moral que a comunidade faz em relação a uma mulher adúltera, em uma região isolada do Brasil, onde a honra do marido traído ainda se lava com sangue.

\section{A mulher e a família matriarcal de baixa renda}

A família matriarcal de baixa renda é o tema de dois filmes: $E u, T u$, Eles, de Andrucha Waddington - 2000, e Linha de passe, de Walter Salles e Daniela Thomas - 2008. No primeiro filme, baseado em fatos reais, Darlene é a chefe de uma família fora dos padrões machistas do Nordeste brasileiro, ela convive com três companheiros ao mesmo tempo: Osias, mais velho lhe garante a estabilidade financeira, Zezinho, primo de Osias, é o que lhe dedica carinho e amor incondicionais, e Ciro, rapaz mais jovem que ela, lhe supre o desejo sexual. Por mais improvável que possa aparentar, eles quatro e seus vários filhos conseguem encontrar harmonia na convivência poligâmica encabeçada por Darlene.

O filme Linha de passe retrata a vida de Cleuza, uma empregada doméstica, mãe de quatro filhos de pais diferentes, e grávida de um quinto filho, gravidez esta a qual ela não sabe exatamente quem é o possível pai. As dificuldades financeiras para criar seus filhos, a falta de uma figura masculina que consiga mediar e controlar os constantes conflitos entre eles, e a busca de realização pessoal diante de todo este quadro. $\mathrm{O}$ filme retrata as famílias matriarcais bastante comuns nas periferias do Brasil, a ausência dos pais, a falta de planejamento familiar, além da falta de perspectivas de desenvolvimento profissional para os jovens de periferia.

Cabe destacar, a respeito deste último filme, que a interpretação primorosa da atriz Sandra Corveloni, como a protagonista Cleuza, lhe rendeu, dentre outros prêmios, o Urso de Ouro de Melhor Atriz de 2009, no renomado Festival de Cinema de Berlim. 
Figura 24. A família matriarcal sertaneja Figura 25. A mãe de família na metrópole
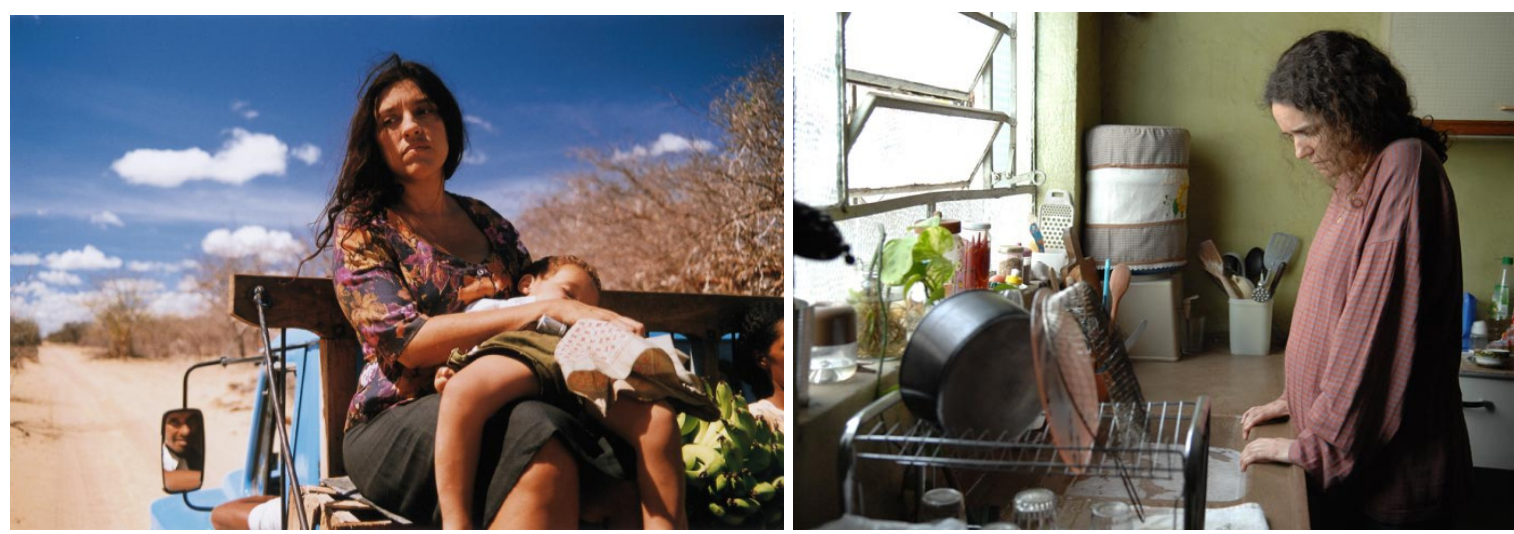

Fonte: Site www.adorocinema.com.br (para as duas imagens).

\section{CONSIDERAÇÕES FINAIS}

O inventário fílmico, ora apresentado e analisado, permitiu debater nove questões fundamentais sobre as representações da mulher no cinema brasileiro contemporâneo: 1. A imagem da mulher enquanto objeto de desejo sexual; 2. A exploração sexual feminina; 3. A mulher e seu envolvimento com o crime; 4. O papel social da jovem mulher negra da periferia; 5. A homoafetividade feminina; 6. A mulher e o romantismo no mundo contemporâneo; 7. A mulher jovem e suas questões existenciais; 8. A mulher e a crise matrimonial; 9. A família matriarcal de baixa renda.

O conjunto das obras analisadas demonstram que, se por um lado ainda persiste a representação da mulher enquanto objeto de desejo sexual, em alguns poucos filmes, por outro lado, a mulher passa a ser representada enquanto protagonista de sua vida, em maior parte dos filmes analisados. E o quadro apresentado evidencia que algumas questões prementes sobre a mulher têm sido trazidas à discussão através dos filmes: os direitos da mulher, a busca pela realização sexual, a crise da instituição social do casamento, as dificuldades em conciliar vida profissional e vida familiar, dentre outros.

As discussões aqui apresentadas não se esgotam neste artigo, pelo contrário, esta é uma contribuição inicial que deverá ser aprofundada em estudos futuros. Outros pesquisadores e, sobretudo, pesquisadoras, que se interessem pelo tema sintam-se convidados (as) a estabelecer diálogo com o autor, a tecer comentários e críticas que possam contribuir com o aprimoramento das análises desenvolvidas. 


\section{REFERÊNCIAS}

ADORO CINEMA - SITE. Obtenção das imagens utilizadas no artigo. In: <http://www.adorocinema.com.br>. Acesso: 21 de outubro de 2014.

AZEVEDO, Paula Tatiane de. Até onde você iria por um filho?: representações de gênero e maternidade no cinema. Trabalho de Conclusão de Curso (Especialização em Educação, Sexualidade e Relações de Gênero). Universidade Federal do Rio Grande do Sul/Programa de Pós-Graduação em Educação, 2011, 45 p.

FURTADO, Marcelo Pais Tabachi. Espectros e Silhuetas em uma Cidade: Imagens da Mulher no Cinema Brasileiro de 1896 a 1928. Trabalho de Conclusão de Curso (Mestrado em Bens Culturais e Projetos Sociais). Rio de Janeiro - RJ: Fundação Getúlio Vargas/Mestrado Profissionalizante em Bens Culturais e Projetos Sociais, 2006, 160 p.

GUBERNIKOFF, Giselle. A imagem: representação da mulher no cinema. Conexão Comunicação e Cultura. Caxias do Sul - RS: Universidade de Caxias do Sul, 2009, vol. 8, n $^{\circ}$ 15 , p. 65-77.

LAHNI, Cláudia Regina; ALVARENGA, Nilson Assunção; PELEGRINI, Mariana Zibordi e PEREIRA, Maria Fernanda França. A mulher negra no cinema brasileiro: uma análise de Filhas do Vento. Revista Científica Centro Universitário Barra Mansa. Barra Mansa - RJ: Centro Universitário Barra Mansa, 2007, vol. 9, n 17, p. 80-88.

LUNA, Ianni Barros. O Estupro e a "norma” de Gênero no Cinema. Dissertação (Mestrado em História). Brasília - DF: Universidade de Brasília/Programa de Pós-Graduação em História, 2006, 87 p.

MACHADO, Liliane Maria Macedo. E a mídia criou a mulher: como a TV e o cinema constroem o sistema de sexo/gênero. Tese (Doutorado em História). Brasília - DF: Universidade de Brasília/Programa de Pós-Graduação de História, 2006, 244 p.

OLIVARES, Rosa Chiquinquirá Raydán. La mirada feminina en el cine venezolano. Dissertação (Mestrado em Comunicação). Quito - EQU: Universidad Andina Simón Bolívar Sede Ecuador/Programa de Maestría en Estudios de la Cultura, 2010, 153 p. 
QUINTERO, Alba Yaneth Niño. Imágenes femininas del cine silente colombiano, 1924-1926. Dissertação (Mestrado em Estudos de Gênero). Bogotá - COL: Universidad Nacional de Colombia/Facultad de Ciencias Humanas, 2010, 149 p.

SILVA, Alberto da. Quando as mulheres filmam: História e gênero no cinema dos anos da ditadura. Esboços. Florianópolis - SC: Universidade Federal de Santa Catarina, 2012, vol. 19, no 27 , p. 14-31.

\section{FILMOGRAFIA}

AÏNOUZ, Karim. O céu de Suely. Rio de Janeiro - RJ: Videofilmes, 2006.

ALVARENGA JÚNIOR, José. Divã. Rio de Janeiro - RJ: Total Entertainment, 2009.

AMARAL, Tata. Antônia. São Paulo-SP: Coração da Selva Transmídia, 2007.

BALDINI, Marcus. Bruna Surfistinha. Rio de Janeiro - RJ: TV Zero Cinema Ltda., 2011.

BRANT, Beto e CIASCA, Renato. Eu receberia as piores notícias dos seus lindos lábios. São Paulo - SP: Drama Filmes, 2011.

BRANT, Beto. Crime delicado. São Paulo - SP: Drama Filmes, 2006.

DHALIA, Heitor. Nina. São Paulo - SP: Gullane Filmes, 2004.

DURAN, Jorge. Proibido proibir. Rio de Janeiro - RJ: El Desierto Filmes, 2007.

GERBASE, Carlos. 3 Efes. Porto Alegre - RS: Casa de Cinema de Porto Alegre, 2007.

GOMES, Marcelo. Era uma vez eu Verônica. São Paulo - SP: Dezenove Som e Imagem Produções, 2012.

LAFFITTE, Marcelo. Elvis \& Madona. Salvador - BA: Hamaca Produções Artísticas Ltda., 2011.

LAGEMANN, Rudi. Anjos do sol. Rio de Janeiro - RJ: Cara de Cão Produções, 2006.

MARTINO, Malu de. Como esquecer. Rio de Janeiro - RJ: E. H. Filmes, 2010.

PEREIRA, Luis Antonio. Jogo de xadrez. Rio de Janeiro - RJ: Ecletic Entertainment, 2014. 
PRADO, Marcos. Paraísos artificiais. Rio de Janeiro - RJ: Zazen Produções, 2012.

REICHENBACH, Carlos. Falsa loura. São Paulo - SP: Dezenove Som e Imagem Produções, 2008 .

REICHENBACH, Carlos. Garotas do ABC. São Paulo - SP: Dezenove Som e Imagem Produções, 2004.

RICCELLI, Carlos Alberto. Onde está a felicidade?. São Paulo - SP: Pulsar Produções Artísticas e Culturais, 2011.

ROA, Gustavo Nieto. Entre lençóis. São Paulo - SP: Centauro Filmes, 2008.

SALLES, Walter e THOMAS, Daniela. Linha de passe. Rio de Janeiro - RJ: Videofilmes, 2008.

SANTUCCI, Roberto. De pernas pro ar. Rio de Janeiro - RJ: Morena Filmes, 2011.

TIKHOMIROFF, Michel. Confia em mim. São Paulo - SP: Mixer, 2014.

TORRES, Cláudio. A mulher invisível. Rio de Janeiro - RJ: Conspiração Filmes, 2009.

WADDINGTON, Andrucha. Eu, Tu, Eles. Rio de Janeiro - RJ: Conspiração Filmes, 2000.

WERNECK, Sandra. Sonhos roubados. Rio de Janeiro - RJ: Cineluz Produções Cinematográficas, 2010. 
(C) Copyright Tiago de Almeida Moreira, 2015

(C) Copyright GeoGraphos, 2015.

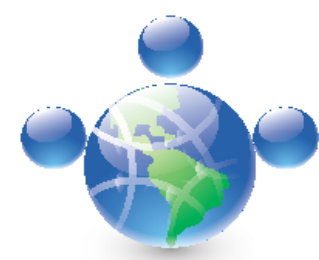

GIECRYAL

GRUPO INTERDISCIPLINARIO DE

ESTUDIOS CRITICOSY DE AMÉRICA LATINA 